\title{
Failures' Study of a New Character Three-Phase High Voltage Supply for industrial Microwave Generators with one magnetrons per Phase
}

\author{
R. Batit ${ }^{1 *}$, M. Chraygane ${ }^{1}$, M. Ferfra ${ }^{2}$ and B. Bahani ${ }^{1}$ \\ ${ }^{I}$ Agadir High School of Technology, MSTI Research Team, Ibnou Zohr University, Agadir-Morocco \\ ${ }^{2}$ Mohammadia's School of Engineers, Research Team in Electrical Energy \& Control, Mohamed V University, Rabat-Morocco
}

Received 02 November 2015; Accepted 11 April 2016

\begin{abstract}
This article treats the development of one of the equivalent electrical models for a single phase power supply for one magnetron; in particular that of its own high voltage (HV) transformer newly dimensioned. This single phase system supplies a voltage doubler and current stabilizer circuit, which supplies a single magnetron. Then, by star connecting the three identical models of the single-phase power supply for one magnetron, we obtain a new character three-phase high voltage power supply for industrial microwave generators with one magnetron per phase. The simulation with EMTP (Electro Magnetic Transcients Program) in nominal operation has given the theoretical results close to the experimental measurements. Finally, the magnetrons' failure of the microwave generator was also treated and allowed to observe the interaction's influence between magnetrons; also the regulation of the anode current has been achieved successfully.
\end{abstract}

Keywords: Three phase character, Magnetron, Microwaves, Failures'study, Control process, EMTP

\section{Introduction}

Figure 1 shows the schematic diagram of the new three-phase high voltage power supply for one magnetron per phase [1][2][3][4], which corresponds to a star connection of three equivalent electrical models of the single-phase power supply for one magnetron. It is composed of an equivalent electrical model of its corresponding single-phase HV transformer with magnetic leakage flux [5][6][7][8], which supplies one voltage doubler and current stabilizer circuit that supplies one magnetron. In the first part of this article, we present a global equivalent circuit diagram of this power supply. The simulation with EMTP [9][10][11] of the new three-phase high voltage power supply's nominal operation allowed to observe its different time curves of different currents and voltages in order to be compared with those obtained experimentally in conventional single-phase high voltage power supply for single magnetron [12][13][14]. The anode current regulating process in each magnetron has been completely verified.

The second part of this article was devoted to studying the influence of the magnetrons' failure on the new three-phase high voltage power supply for one magnetron per phase. In this failure's study; we will successively analyze the following cases:

- One faulty magnetron and two magnetrons in service.

- Two faulty magnetrons and one magnetron in service.

- Three faulty magnetrons.

2. Modeling of the new character three-phase high voltage power supply for one magnetron per phase

\footnotetext{
*E-mail address: redouane.batit@edu.uiz.ac.ma ISSN: 1791-2377 @ 2016 Eastern Macedonia and Thrace Institute of Technology. All rights reserved.
}

\subsection{Equivalent circuit model of Single-phase high voltage} power supply for two magnetrons.

Fig. 2 refers to the equivalent circuit diagram of this power supply; in particular that of the quadrupole model in $\pi$ of its single phase transformer [5][6][12]. Each of the three saturable inductors is a function of its own reluctance [11][13][14], so it's also a function of its own permeability in a précised part of the correspondent magnetic circuit, which is supposed fictitiously closed, and in which $\mathrm{n}_{2}$ secondaries turs are rolled. This model was successfully verified $[2][3][4][15]$ and showed that each magnetron delivers its full desired power.

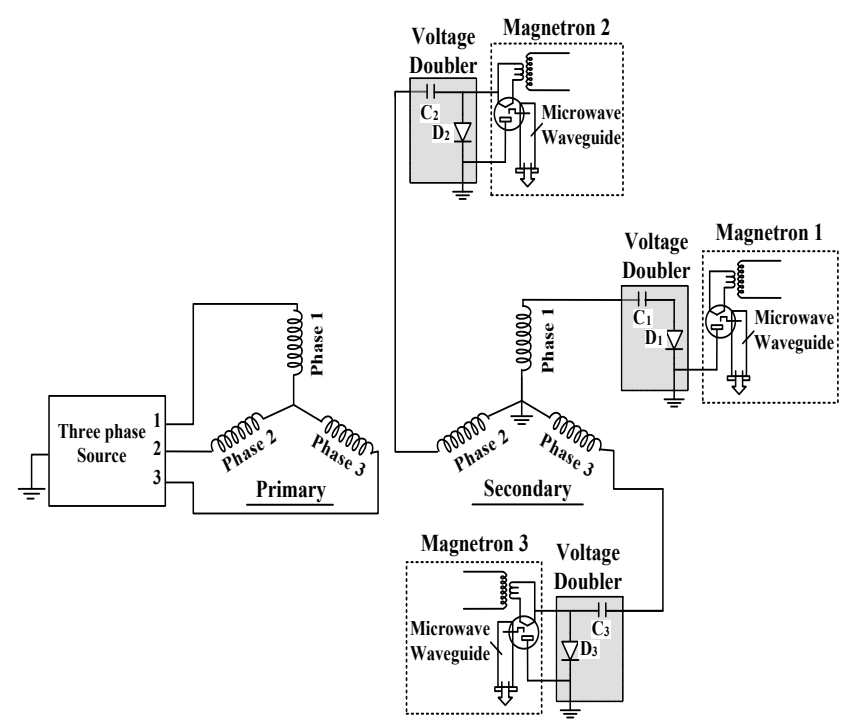

Fig. 1. Character three phase high voltage power supply for one magnetron per phase. 


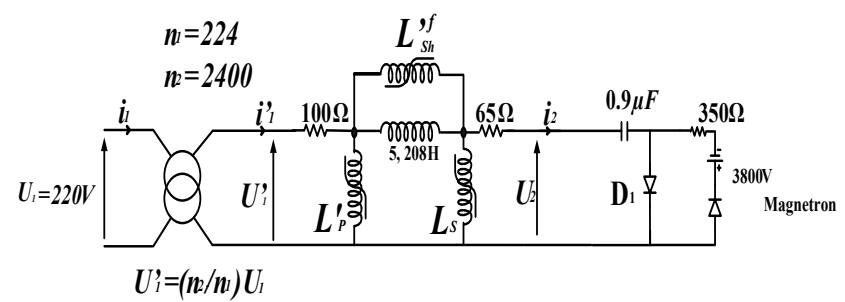

Fig. 2. Electrical equivalent model of the single phase high voltage power supply for one magnetron

\subsection{Simulation with EMTP of the new three-phase high} voltage power supply for one magnetron per phase.

This new system in the fig. 1 and fig. 3 was obtained from star coupling the three identical models, which are described in fig. 2. These three models will be supplied respectively by single-phase voltages with the same R.M.S. value of the voltage 220 Volts $-50 \mathrm{~Hz}$, and a phase difference of 120 degree.

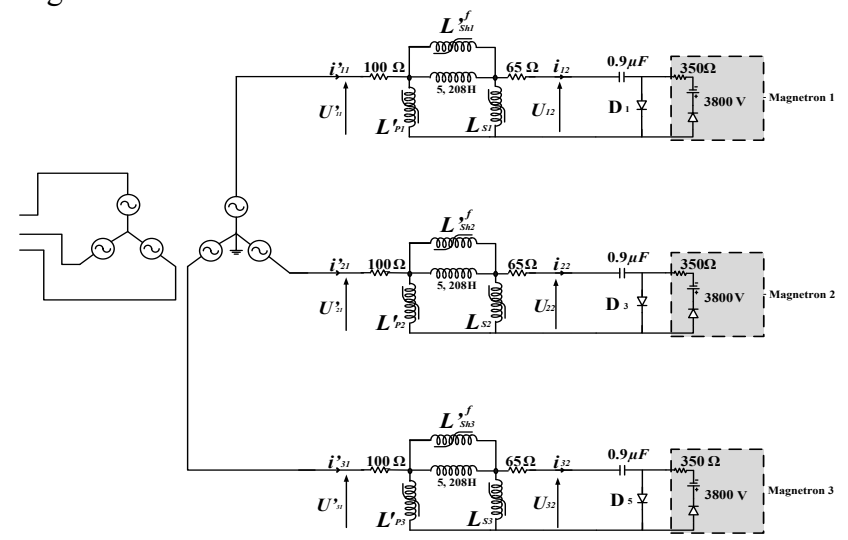

Fig. 3. Character three phase high voltage power supply for one magnetron per phase (Equivalent circuit model)

The simulation with EMTP [16][17][18] of electrical nominal functioning of the assembly in fig. 3 allowed to observe the time curves (in fig. 4(A)) of voltages (condensers, magnetrons, secondaries) and currents (diodes, magnetrons, secondaries).

For each magnetron of one phase in nominal operation $(220 \mathrm{~V}$ and $50 \mathrm{~Hz}$ in primary side), the electric current's signals (diodes, magnetrons and secondaries) and voltages (condensers, magnetrons and secondaries) may constitute an assembly which have the same form as that of single magnetron's conventional power supply. These signals are periodic variable quantities (but they are not sinusoidal), globally for all three phases simultaneously feeding two magnetrons, therefore there are three successive sets of signals which are phase shifted by 120 degrees.

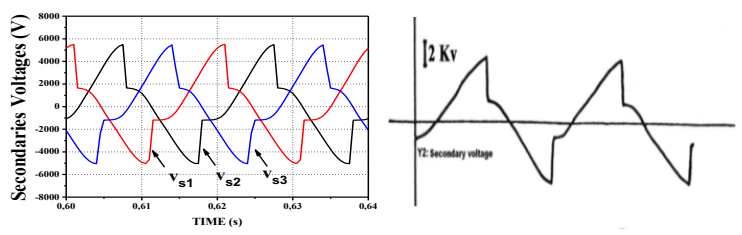

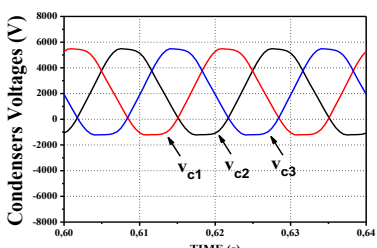
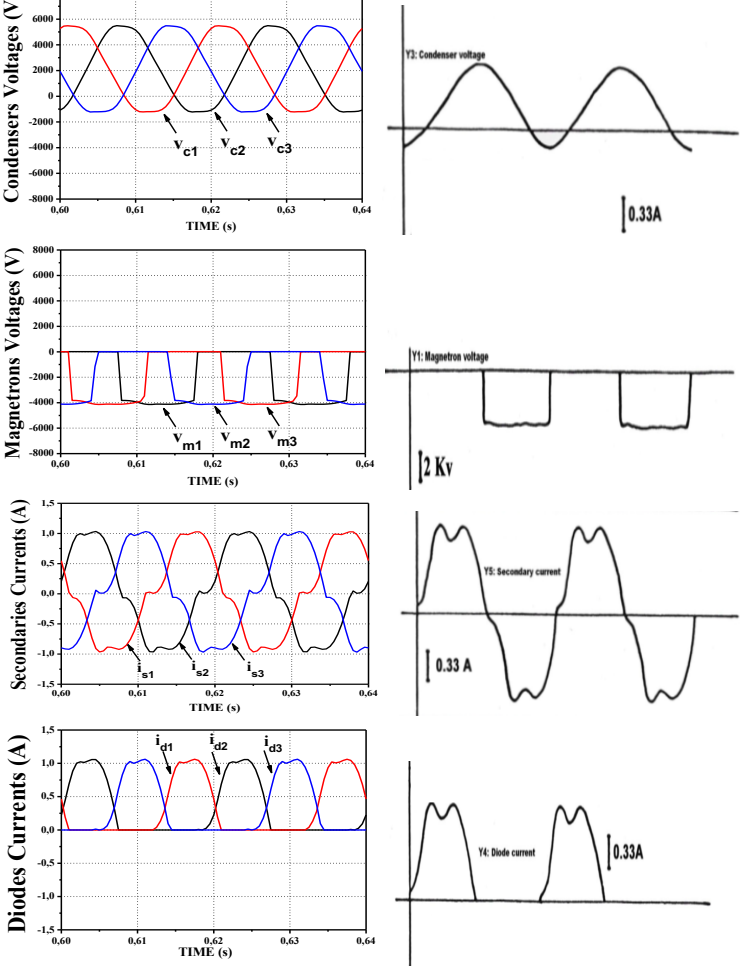

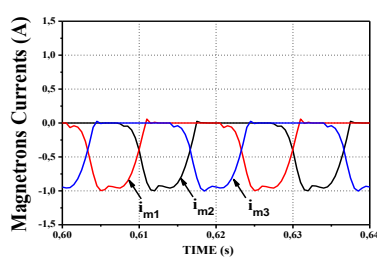

(A)

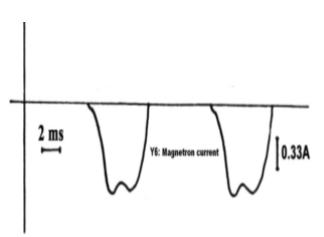

(B)
Fig. 4. (A) The simulation's results with EMTP of a character three phase high voltage power supply for one magnetron per phase.(B) The experimental waveforms of currents and voltages of a single phase high voltage power supply for one magnetron (nominal mode)

It is affirmed that the curves obtained through simulation in EMTP [16][18][21] of the new power supply's three-phase device of one magnetron per phase (in non-linear regime), are in accordance with the experimental waveforms recorded in the case of single magnetron's single-phase power supply (fig.4.B).

The pace obtained of each magnetron's current reflects the flow of its full useful power. So the phase shift between the three magnetrons' currents (which equals 120 degrees) confirms the absence of interaction between the magnetrons of one phase and those of next phase. The operating points of all magnetrons are no longer disturbed.

During the simulation with EMTP [19][20][21] of this new three phase character high voltage power supply of one magnetron per phase, the current's regulation process in each of the three magnetrons of the microwave's generator was verified while observing the stability of the variations in current in each magnetron compared to those in primary voltage ( $\pm 10 \%$ of nominal voltage). The fig. 5 shows the current's waveforms in each magnetron corresponding to the respective values of $200 \mathrm{~V}$ and $240 \mathrm{~V}$ for primary voltage in the supply network. 

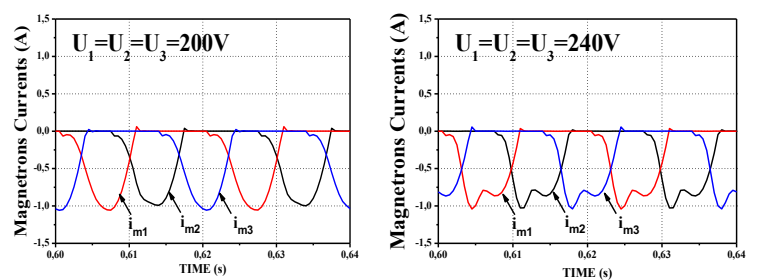

Fig. 5. Stabilization of the anode current of the magnetron in relation with variations in the mains voltage $+10 \%$ of the nominal voltage

It is noted that the maximum value of the current's amplitude in each of the two identical magnetrons in each of the three phases remains below an acceptable limit $\left(\mathrm{I}_{\max }<1.2 \mathrm{~A}\right)$, which respects the constraints imposed and recommended by the manufacturer of magnetrons, therefore it ensures the correct operation of microwave's tube with reasonable average current $(300 \mathrm{~mA})$ without exceeding the recommended peak current. Given the above, the current's stabilization process in each magnetron is completely verified.

\section{New three phase character HV power supply: study of magnetrons' failure}

Table 1. The possible failures' cases of three magnetrons for the studied microwave generator:

\begin{tabular}{|l|lll|}
$\begin{array}{l}\text { Types of } \\
\text { magnetron's } \\
\text { failures }\end{array}$ & Phase I & Phase II & Phase III \\
\hline $\begin{array}{l}\text { One faulty / } \\
\text { Two in service }\end{array}$ & $\begin{array}{l}\text { One faulty } \\
\text { magnetron }\end{array}$ & $\begin{array}{l}\text { One } \\
\text { magnetron } \\
\text { in service }\end{array}$ & $\begin{array}{l}\text { One } \\
\text { magnetron } \\
\text { in service }\end{array}$ \\
\hline $\begin{array}{l}\text { Two faulty / } \\
\text { One in service }\end{array}$ & $\begin{array}{l}\text { One faulty } \\
\text { magnetron }\end{array}$ & $\begin{array}{l}\text { One faulty } \\
\text { magnetron }\end{array}$ & $\begin{array}{l}\text { One } \\
\text { magnetron } \\
\text { in service }\end{array}$ \\
\hline Three faulty & $\begin{array}{l}\text { One faulty } \\
\text { magnetron }\end{array}$ & $\begin{array}{l}\text { One faulty } \\
\text { magnetron }\end{array}$ & $\begin{array}{l}\text { One faulty } \\
\text { magnetron }\end{array}$ \\
\hline
\end{tabular}

The electrical behavior's simulation through EMTP [17][18][20][21] of three-phase high voltage power supply for one magnetron per phase was performed for each case of failure which is shown in Table 1. The observation of the waveforms obtained from the currents and voltages allowed analyzing the different characteristics of high voltage circuit and particularly that of magnetron's current.

\subsection{Case of one faulty magnetron and two magnetrons in service.}

The simulation's results with EMTP [22][23][24] of the assembly in Fig. 6. (A) are shown in Fig. 6. (B). It is noted that the faulty magnetron reduces the operation of its corresponding voltage doubler, consisting of diode and capacitor $0.9 \mu \mathrm{F}$ at the level of this capacitor's loading through the diode with the secondary peak voltage supplied by the high voltage transformer.

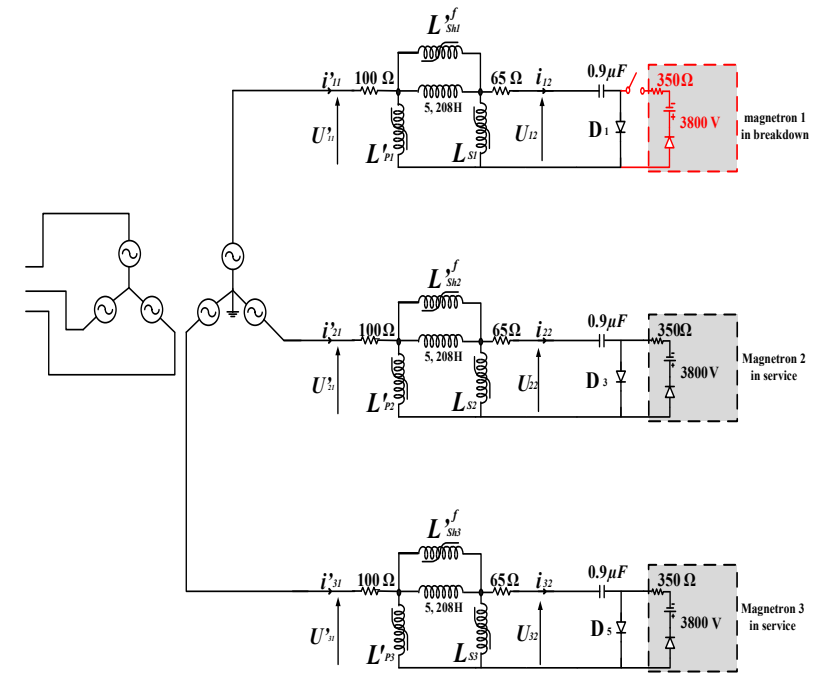

Fig. 6. (A) Circuit model of a character three phase HV power supply for $\mathrm{N}=1$ magnetrons per phase. Case of one faulty magnetron in the phase 1 .
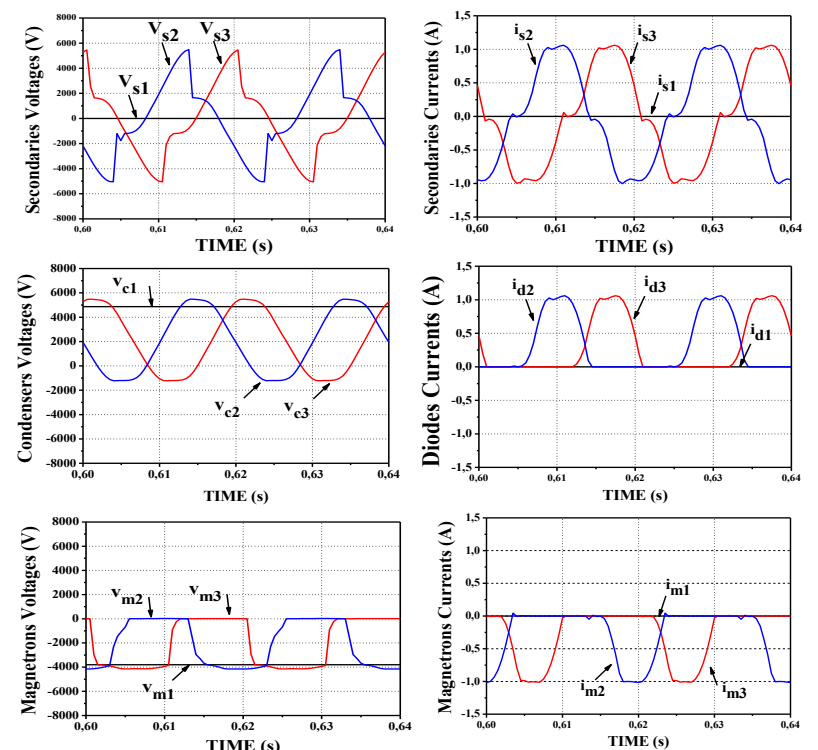

Fig. 6. (B) Waveforms of currents and voltages of the circuit in fig. 6 . (A). Case of one faulty magnetron in the phase 1 .

The faulty magnetron of one phase has no interaction effect on the operation of the two other functional magnetrons. Given that their operating points are not disturbed.

The current's control process in each of the two magnetrons in service of microwave's generator was verified through simulation with EMTP [20][25][26] in which we observe (for this new three-phase high voltage power supply of two magnetrons per phase) the stability of the variations in current in each magnetron compared to those in primary voltage ( $\pm 10 \%$ of nominal voltage). The fig. 7 shows the current's waveforms in each magnetron corresponding to the respective values of $200 \mathrm{~V}$ and $240 \mathrm{~V}$ for primary voltage in supply network. 

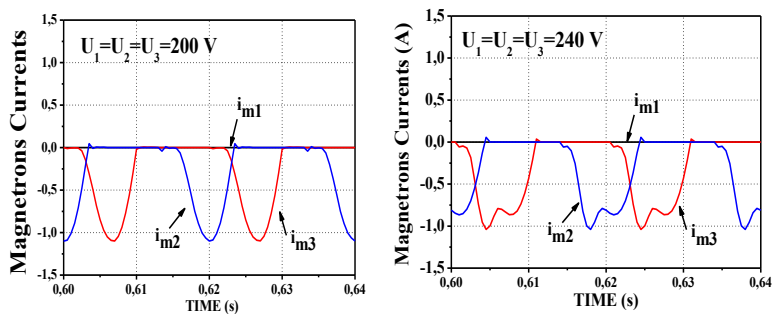

Fig. 7. Stabilization of the anode current of the magnetron in relation with variations in the mains voltage $+10 \%$ of the nominal voltage

It is noted that the maximum value of the current's amplitude in each magnetron in each of the two phases 2 and 3 remains below an acceptable limit $(<1.2 \mathrm{~A})$, which respects the constraints imposed and recommended by the manufacturer of magnetrons, therefore it ensures the correct operation of microwave's tube with reasonable average current $(300 \mathrm{~mA})$ without exceeding the recommended peak current. Given the above, the current's stabilization process in each magnetron is completely verified.

\subsection{Case of two faulty magnetrons and one magnetron in service}

The simulation's results through EMTP [18][23][26] of the assembly in Fig. 8. (A) are shown in Fig. 8.(B). It is noted that each of the two faulty magnetrons reduces the functioning of its corresponding voltage doubler, consisting of diode and capacitor $0.9 \mu \mathrm{F}$ at the level of this capacitor's loading through the diode with the secondary peak voltage supplied by the high voltage transformer. Each of the two faulty magnetrons doesn't disturb the functioning of the other magnetron in service.

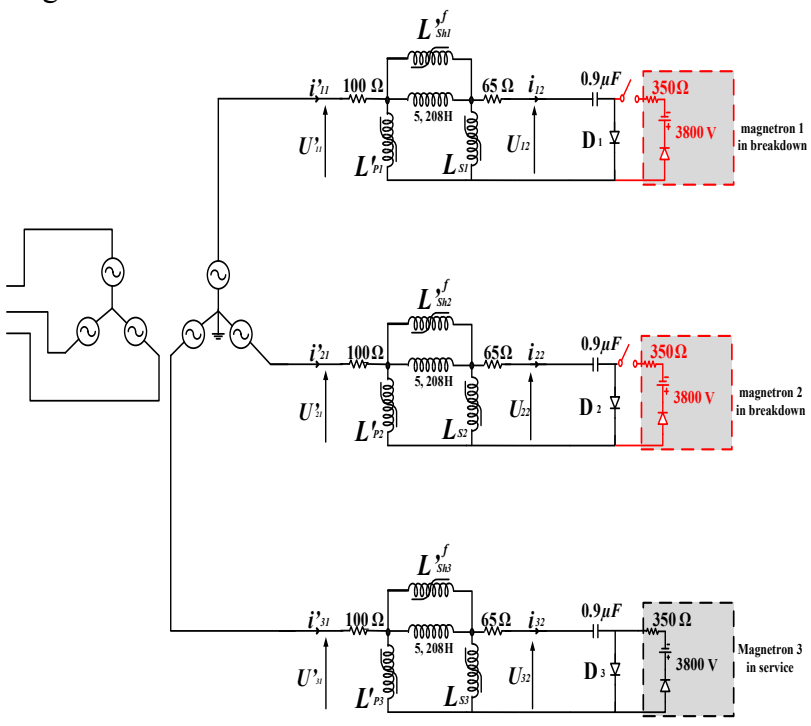

Fig. 8. (A) Circuit model of a character three phase HV power supply for one magnetron per phase. Case of Two faulty magnetrons (phase 1 and phase 2)

The two faulty magnetrons of the two phases (phase 1 and phase 2) have no interaction effect on the functioning of the other functional magnetron (of phase 3). Given that their operating points are not disturbed.
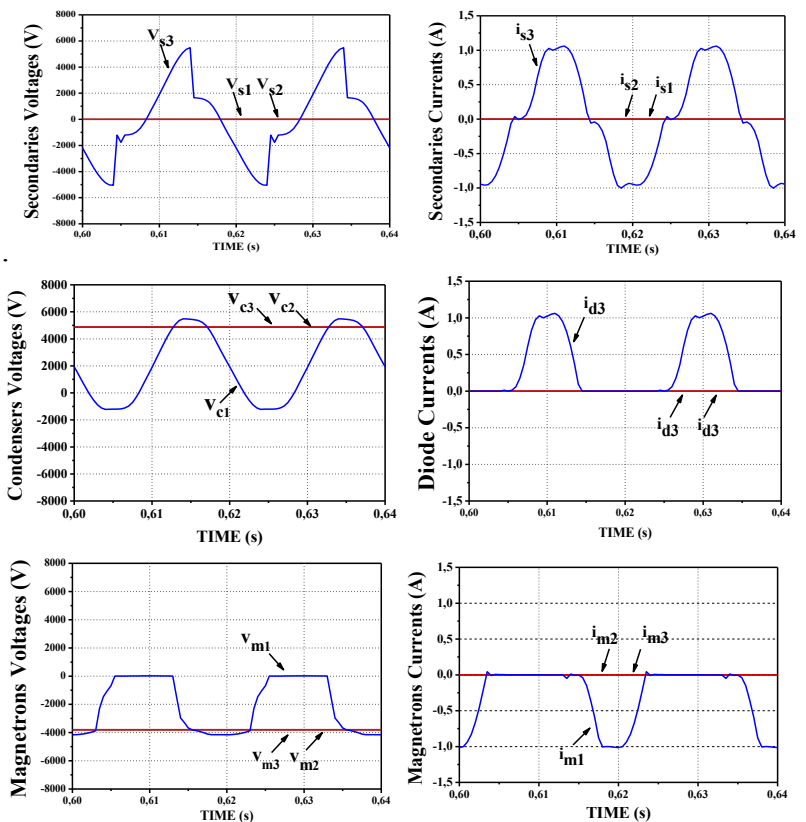

Fig. 8. (B) Waveforms of currents and voltages of the circuit in fig. 8 . (A). Case of Two faulty magnetrons (phase1 and phase2).

The current's control process in the magnetron in service of microwave's generator was verified through simulation with EMTP [17][22][23] in which we observe (for this new three-phase high voltage power supply of two magnetrons per phase) the stability of the variations in current in functional magnetron compared to those in primary voltage $( \pm 10 \%$ of nominal voltage). The fig. 7 shows the current's waveforms in each magnetron corresponding to the respective values of 200 Volts and 240 Volts for primary voltage in supply network.
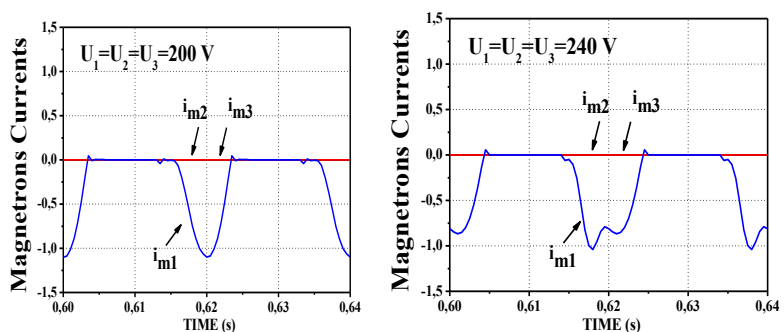

Fig.9. Stabilization of the anode current of the magnetron in relation with variations in the mains voltage $+10 \%$ of the nominal voltage

It is noted that the maximum value of the current's amplitude in functional magnetron remains below an acceptable limit $(<1.2 \mathrm{~A})$, which respects the constraints imposed and recommended by the manufacturer of magnetrons, therefore it ensures the correct operation of microwave's tube with reasonable average current $(300 \mathrm{~mA})$ without exceeding the recommended peak current. Given the above, the current's stabilization process in each magnetron is completely verified.

\subsection{Case of three faulty magnetrons.}

The simulation's results through EMTP [23][25][26] of the assembly in Fig 10A are shown in Fig 10B. It is noted that each faulty magnetron in each phase reduces the functioning of its corresponding voltage doubler, consisting of diode and capacitor $0.9 \mu \mathrm{F}$ at the level of this capacitor's loading 
through the diode with the secondary peak voltage supplied by the high voltage transformer. In order to find the maximal debit of microwaves' power, we have just to replace the defective magnetrons with the new ones.

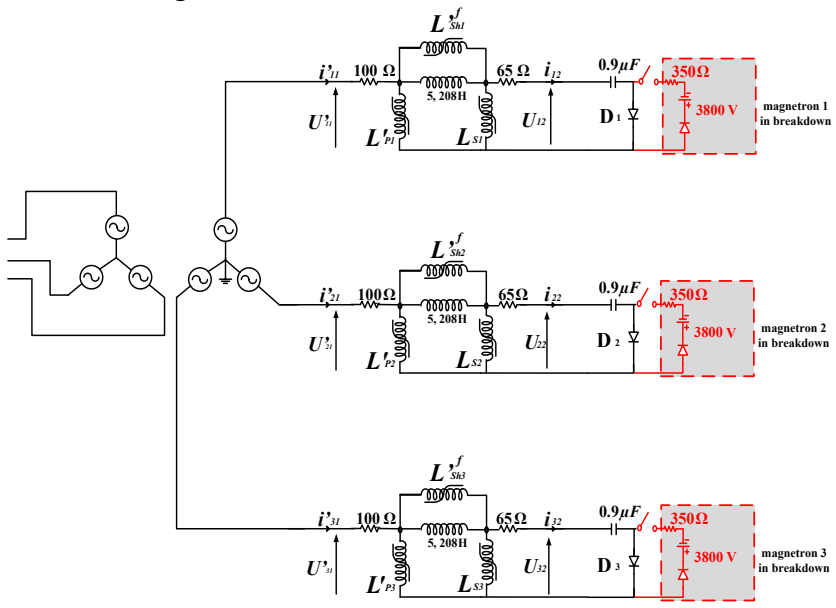

Fig. 10. (A) Circuit model of a character three phase HV power supply for one magnetron per phase. Case of three faulty magnetrons per phase.
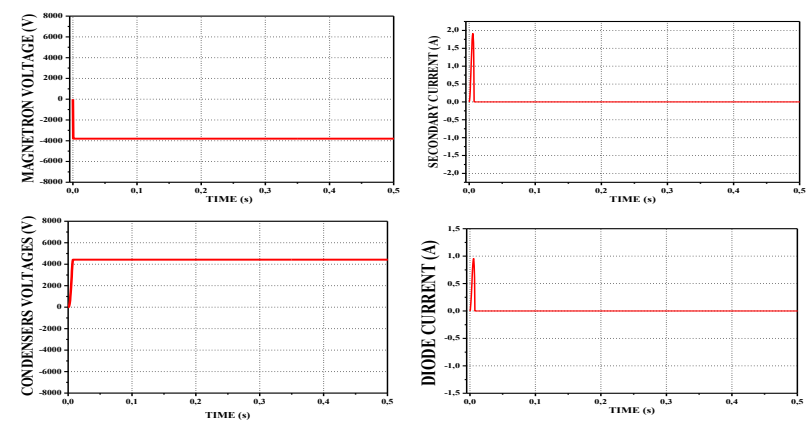
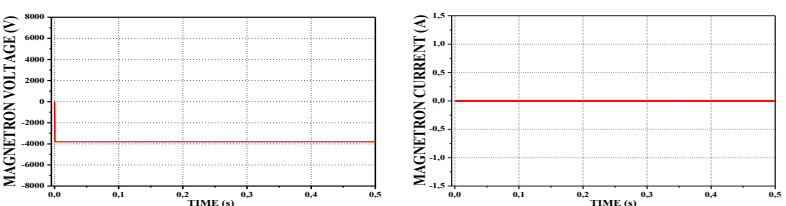

Fig. 10. (B) Waveforms of currents and voltages of the circuit in fig. 10 (A). Case of two faulty magnetrons per phase.

\section{Conclusion}

We have described in this article a study of the nominal operation's feasibility using EMTP of a new character threephase high voltage power supply for microwave generators with two magnetrons 800 Watts per phase which can deliver up to 4800 Watts useful power at $2450 \mathrm{MHz}$.

The simulation with the EMTP code of the new power supply with one magnetron per phase allowed us to verify the current control process in each magnetron; which ensures the protection of all magnetrons against any possible variation in voltage entrance of the three-phase supply network.

The feasibility test of the electrical operating under nominal conditions of the new three-phase character power supply system with one magnetron per phase has been proved conclusive. It can be extended without any problem in the case of a power supply with $\mathrm{N}=2,3, \ldots 10$ magnetrons per phase at nominal conditions.

On the other hand, the failure of $\mathrm{M}$ among the $\mathrm{N}(\mathrm{N}=3)$ powered magnetrons does not change the functioning of the $(\mathrm{N}-\mathrm{M})$ remaining functional magnetrons $(\mathrm{M}<=\mathrm{N})$.

The study of feasibility of the new three-phase power supply with multi magnetrons per phase (one magnetron per phase in our case), led us to initiate the study of the real three-phase power supply with multi magnetrons per phase by modeling and dimensioning adequately its new own correspondent three-phase shunts transformer, which reduces the size, volume, weight and electrical wiring then reduce the cost of implementation and maintenance of microwaves generators.

\section{References}

1. M. BASSOUI, M. FERFRA, M. CHRAYGANE, M. OULD AHMEDOU, N. ELGHAZAL \& B. BAHANI "Modeling of new high voltage power supply with three-phase character for microwaves generators with one magnetron by phase under matlab simulink code",ARPN - Journal Of Engineering And Applied Sciences, VOL. 9, NO. 12, DECEMBER 2014

2. M.BASSOUI, M.FERFRA, M.CHRAYGANE, M.OULD AHMEDOU, N.ELGHAZAL, B.BAHANI, A.BELHAIBA "Energy balance of optimized three-phase high voltage power supply for microwaves generators with $\mathrm{n}$ magnetrons by phase (treated case $\mathrm{n}=1)$.", Journal of Theoretical and Applied Information Technology (JATIT), Vol. 62 No.2, 20 Avril 2014

3. OULD.AHMEDOU.M, BASSOUI.M, FERFRA.M, CHRAYGANE.M, BELHAIBA.A, EL GHAZAL.N, BAHANI.B , "global modeling of a new three phase hv power supply for microwaves generators with $\mathrm{n}$ magnetrons by phase (treated case $\mathrm{n}=1$ ) under Matlab simulink code", Journal of Theoretical and Applied Information Technology (JATIT), Vol. 61 No.1, 10 Mars 2014

4. N. EL GHAZAL, M. OULD AHMEDOU, M. CHRAYGANE, M. FERFRA, A. BELHAIBA, "Optimization of high voltage power supply for industrial microwave generators for one magnetron.", Journal Of Theoretical And Applied Information Technology, vol. 46 no. 1 , pp $001-010$; (2012)

5. Chraygane M, "Modélisation avec EMTP d'une nouvelle génération d'alimentation haute tension monophasée pour générateurs microondes à magnétrons destinés aux applications industrielles. "
Thèse de doctorat d'état, Université Ibn Zohr Agadir, Maroc, $\mathrm{n}^{\circ}$ 113/07 (2007).

6. M. CHRAYGANE, M. TEISSIER, A. JAMMAL, J.P. MASSON, "Modélisation d'un transformateur à shunts utilisé dans l'alimentation H.T d'un générateur micro-ondes à magnétron.",Journal de physique III, (1994) 2329-2338

7. M. CHRAYGANE, M. FERFRA, B. HLIMI , "Modélisation d'une alimentation haute tension pour générateurs micro-ondes industriels à magnétron", Revue 3EI, 41 (2005) 37-47.

8. M. OULD AHMEDOU, M. CHRAYGANE \& M. FERFRA, "New Model Validation Approch to the Leakege Flux transformer of a High Voltage Power Supply Used for Magnetron for The Industrial Microwaves Generators 800 Watts-2450 Mhz", International Review of Electrical Engineering (IREE), Vol 5, N³, June 2010.

9. Hermann W Dommel. ElectroMagnetic Transcients Program, Reference Manual, EMTP Theory Book. 1986

10. Van Dommelen D. ATP General Introduction, Leuven EMTP Summer Course. 1991.

11. W Scott Meyer et Tsu-huei Liu. "Alternative Transients Program (ATP), Rule Book, Canadian/american" EMTP User group, 1987; 92.

12. A. BELHAIBA, M. OULD AHMEDOU, M. CHRAYGANE, $M$ FERFRA, N. ELGHAZAL, "Energy balance of optimized high voltage power supply for microwaves generators used in various industrial applications", International Review Of Modelling And Simulations (iremos), vol.5, n.4, august 2012, pp. 1460-1469 
13. B. Kawkabani, J.-J. Simond, "Improved Modeling of Three-Phase Transformer Analysis Based on Magnetic Equivalent Circuit Diagrams And Taking Into Account Nonlinear B-H Curve", Journal Electromotion, Volume 13, Number 1, January-March 2006, pp. 510.

14. L. Dubé, "European EMTP-ATP Users Groupe.V, Users Guide to models in ATP", (1996).

15. N. EL GHAZAL, M. CHRAYGANE, M. FERFRA, A. BELHAIBA, M. FADEL, B.BAHANI, "Modeling of new three-phase high voltage power supply for industrial microwave generators with one magnetron per phase", International Journal Of Electrical And Computer Engineering, IJECE, vol 3, no 2; pp 31-38 (april 2013)

16. Hermann W Dommel. ElectroMagnetic Transcients Program, Reference Manual, EMTP Theory Book. 1986

17. Van Dommelen D. ATP General Introduction, Leuven EMTP Summer Course. 1991.

18. W Scott Meyer et Tsu-huei Liu. "Alternative Transients Program (ATP), Rule Book, Canadian/american" EMTP User group, 1987; 92.

19. L. Dubé, "European EMTP-ATP Users Groupe.V, Users Guide to models in ATP", (1996).

20. Hans K. Hoidalen, "Atpdraw for Windows, Atp draw Version 3 User Manuel (Atpdraw Installation Manual, Atpdraw Introductory
Manual, Atpdraw advanced Manuel)," European EMTP-ATP Users Group e.V, (1996).

21. M. Kizilcay et L. Prikler, European EMTP ATP Users Group e.V, EEUG News, Number 3, Volume 3, (1997).

22. M. Kizilcay et L. Prikler, "ATP-EMTP Beginner's Guide for EEUG Members," European EMTP-ATP Users Group e.V, (2000).

23. H.W. Dommel, "Transformer models in the simulation of electromagnetic transients," Fifth Power Systems Computation Conference, England. Comm., (1975).

24. Chan J. H., Vladimirescu A., Gao X. C., Liebmann P., Valainis J., "Non linear transformer model for circuit simulation," IEEE Transactionson Computer-Aided, $\mathrm{N}^{\circ} 4,10,(1991)$.

25. Mukerji, Saurabh Kumar; Goel, Sandeep Kumar; Basu, Kartik Prasad, "Experimental determination of equivalent-circuit parameters for transformers with large series-branch impedances", International Journal of Electrical Engineering Education, vol 43, November 2006 , pp. 352-357.

26. J.Arrilaga, W.Enright, N.R.Watson, A.R.Wood "Improved simulation of HVDC converter transformers in the electromagnetic transient programs", IEEE Proc-Gener. Transm. Distrib, vol. 144. No 2, March 1997. 